\title{
High-Sensitivity CRP is Associated with Serum 25-Hydroxyvitamin D Levels, but is not Affected by 5-Year Supplementation with Cholecalciferol
}

\author{
Julia Beilfuss ${ }^{1 *}$, Rolf Jorde ${ }^{1,2}$ and Elena Kamycheva ${ }^{1,2}$ \\ ${ }^{1}$ Division of Medicine, University Hospital of North Norway, Tromsø, 9038 Norway \\ ${ }^{2}$ Endocrine Research Group, Institute of Clinical Medicine, Faculty of Medicine, UIT/The Arctic University of Norway, Tromsø 9037, \\ Norway
}

Received: September 01, 2017; Accepted: October 03, 2017; Published: October18, 2017

*Corresponding author: Julia Beilfuss, Division of Medicine, University Hospital of North Norway, Tromsø, 9038 Norway, E-mail: julia.beilfuss@ unn.no

\begin{abstract}
Background: Insufficient vitamin D status has been linked to insulin resistance and cardiovascular disease. Serum 25-hydroxyvitamin D $(25(\mathrm{OH}) \mathrm{D})$ is also involved in immune activation and inflammation. High-sensitivity C-reactive protein (hs-CRP) is an inflammatory biomarker that has been associated with increased risk of cardiovascular disease and metabolic syndrome in observational studies. We aimed to investigate the association between serum 25(OH)D and hs-CRP in an observational study (the sixth Tromsø study), and to evaluate whether supplementation with cholecalciferol has any effect on hs-CRP in an interventional study (the Tromsø vitamin D and type 2 diabetes mellitus trial).

Methods: The association between serum 25(OH) D and hs-CRP was investigated with Pearson's correlation and a linear regression model after adjusting for age, sex, BMI, waist circumference and $\mathrm{HbA}_{1} \mathrm{C}$. Pre-diabetic subjects in the interventional study were randomized into two groups, receiving either 20,000 IU/week of vitamin D or a placebo; the intervention period was five years. Delta values of hs-CRP were recorded (calculated by subtracting hs-CRP at baseline from hs-CRP at the end of each year of intervention). Differences in hs-CRP delta values between the treatment and placebo groups were studied with ANOVA. The logistic regression model was applied to determine whether intervention with vitamin D was a predictor of decreased hs-CRP, after adjusting for age, sex, BMI, $\mathrm{HbA}_{1} \mathrm{c}$ and smoking.
\end{abstract}

Results: The observational study included 10,118 non-smoking subjects, while the intervention included 556 subjects. In the observational study, we found a significant negative correlation between serum 25(OH) D and hs-CRP ( $\mathrm{r}$ coefficient of $-0.05[P=0.001]$ and $\beta$ coefficient of -0.02 $[P=0.03]]$. In the interventional study, there were no significant differences in hs-CRP delta values between the vitamin $\mathrm{D}$ and placebo groups during any year of the 5-year intervention. Supplementation with cholecalciferol did not predict any significant decrease in hs-CRP after adjustments for other factors.

Conclusion: Although there was a significant association between serum 25(OH) D and hs-CRP in the observational study, there was no lowering effect of cholecalciferol supplementation on hs-CRP levels during the 5-year intervention. Thus, the association between serum $25(\mathrm{OH}) \mathrm{D}$ and hsCRP most likely has no obvious clinical importance.

Keywords: 25-hydroxyvitamin D; high-sensitivity CRP; inflammation; cardiovascular disease; diabetes.

\section{List of abbreviations}

25(OH)D; Hs-CRP; CVD; T2DM; TNF- $\alpha$; IL-1; IL-6; BMI; HbA1c; IGT; OGTT; IU, HPLC; LC-MS/MS; CV; RCT; NFKB; VDR; 1,25(OH)2D; NSAIDS; 25-hydroxyvitamin D; high sensitive C-reactive protein; cardiovascular disease; type 2 diabetes mellitus; tumor necrosis factor $\alpha$; interleukin-1; interleukin-6; body mass index; glycated hemoglobin; impaired glucose tolerance; oral glucose-tolerance test; international units; highperformance liquid chromatography; liquid chromatographytandem mass spectrometry; coefficient of variation; randomized -controlled trial; nuclear factor kappa B; vitamin D receptor; 1,25-dihydroxyvitamin D; nonsteroidal anti-inflammatory drugs

\section{Background}

Vitamin D is a fat-soluble vitamin with a main function of maintaining bone mineral content through regulation of calcium and phosphorus homeostasis [1]. In the past few decades, nonclassical actions of vitamin D have been studied with increased attention, such as its impact on innate and adaptive immunity and involvement in immune-mediated disorders such as infections, autoimmune disease and cancer [2-6]. Recent observational studies reported significant associations between low serum 25-hydroxyvitamin D (25(OH) D) concentrations and increased risk of metabolic syndrome, hypertension, hyperglycemia and Cardiovascular Disease (CVD) [7-10]. Inflammation has a 
well-established pathogenic role in these conditions, as well as in obesity and Type 2 Diabetes Mellitus (T2DM) , and obese subjects and/or subjects with T2DM demonstrate elevated levels of inflammatory biomarkers such as fibrinogen, white blood cells and C-Reactive Protein (CRP) [11,12].

CRP is an inflammatory marker that is synthesized and secreted predominantly by hepatocytes in response to proinflammatory cytokines, such as Tumor Necrosis Factor A (TNF- $\alpha$ ), Interleukin-1 (IL-1) and Interleukin-6 (IL-6) [13, 14]. In a number of observational studies, CRP was a strong predictor of metabolic syndrome and cardiovascular disease and the results from the Rotterdam study (a large population-based cohort study) showed that serum CRP was associated with elevated risk of T2DM independent of overweight and obesity [15-19]

High-sensitivity CRP (hs-CRP) measures CRP at very low concentrations, between 3 and $10 \mathrm{mg} / \mathrm{L}$. Hs-CRP is considered to be a biomarker of low-grade inflammation , which is strongly associated with atherosclerosis, obesity and prediabetes[20,21].

The relationship between serum $25(\mathrm{OH})$ D concentrations and CRP (or hs-CRP) has been investigated in several studies, with inconsistent results [22-24]. We have therefore aimed to investigate the association between serum 25(OH)D concentration and hs-CRP based on both an observational study (the sixth Tromsø Study) and a 5-year interventional study (Tromsø vitamin D and T2DM trial: vitamin D vs. placebo in subjects with prediabetes).

\section{Materials and methods}

\section{Observational study: the sixth Tromsø Study}

The Troms $\varnothing$ Study, conducted by the University of Troms $\varnothing$ in cooperation with the National Health Screening Service of Norway, is a longitudinal, population-based, multipurpose study focused on lifestyle-related diseases $[25,26]$. The sixth survey of the Troms $\emptyset$ Study was performed in 2008, in which 19,762 subjects were invited and 12,984 responded. The participants completed questionnaires about lifestyle factors, including consumption of cod liver oil, use of vitamin D supplements, and smoking. Only non-smoking subjects $(n=10,118)$ were included. Non-fasting blood samples were drawn for later measurements of hs-CRP, glycated hemoglobin (HbA1c) and serum.

$25(\mathrm{OH})$ D. Height and weight were measured with the participants wearing light clothing and no shoes. Body mass index (BMI) was calculated as weight (kg) divided by height squared $\left(\mathrm{m}^{2}\right)$. Waist circumference was measured at the level of the navel.

\section{Interventional study (5-year intervention): Tromsø vitamin $D$ and T2DM trial}

The recruitment of subjects and the procedure of randomization is described in detail elsewhere [27].Briefly, the inclusion criteria were age of 21-80 years and a diagnosis of prediabetes. Prediabetes was defined as an impaired fasting glucose (IFG) level of $>6 \mathrm{mmol} / \mathrm{L}$ or $<7.7 \mathrm{mmol} / \mathrm{L}$ ) and/or Impaired Glucose Tolerance (IGT) with a 2-h glucose of $>7.7$ $\mathrm{mmol} / \mathrm{L}$ or $<11.1 \mathrm{mmol} / \mathrm{L}$ on an Oral Glucose-Tolerance Test
[OGTT] using $75 \mathrm{~g}$ if glucose, combined with a fasting glucose level of $<7.0 \mathrm{mmol} / \mathrm{L}$.

The exclusion criteria were a history of coronary infarction, angina pectoris, stroke, sarcoidosis, cancer in the preceding 5 years, renal stones, nut allergies or reduced kidney function (creatinine of $>125 \mu \mathrm{mol} / \mathrm{L}$ in men and $105 \mu \mathrm{mol} / \mathrm{L}$ in women). Subjects were also excluded if they used weight-reducing drugs or antidepressant medications, were pregnant or lactating, or were females younger than 50 years and not using adequate contraception.

Each participant's medical history was recorded, including smoking habits and use of calcium and vitamin D supplementation. Height and weight were measured with the subjects wearing light clothing and no shoes. BMI was calculated as weight $(\mathrm{kg})$ divided by height squared $\left(\mathrm{m}^{2}\right)$. The study medication was cholecalciferol capsules (vitamin D3 20,000 IU [Dekristol; Mibe, Jena, Germany]) or a placebo in the form of identical-looking capsules containing arachis oil (Hasco-Lek, Wroclaw, Poland). The medication or the placebo was taken as one capsule per week. The subjects were not allowed to take vitamin D supplements (including cod liver oil) exceeding $400 \mathrm{IU} /$ day. At the baseline visit, nonfasting blood samples were drawn. Body measurements and laboratory evaluations were repeated annually during the 5-year intervention.

\section{Laboratory measurements}

Height, weight, HbA1c, plasma glucose, serum parathyroid hormone, insulin and hs-CRP were measured. Serum levels of $25(\mathrm{OH}) \mathrm{D}$ in the observational study were measured by immunometry (electro chemiluminiscent immunometric assay) using an automated clinical chemistry analyser (Modular E170; Roche Diagnostics GmbH, Mannheim, Germany). The total analytical Coefficient of Variation (CV) for the vitamin D assay was $7.3 \%$ based on consecutive donor control measurements (65.0 nmol/L) during the analytical period, using a qualitymanagement program (QM; Tieto Enator, Helsinki, Finland). The cross-reactivity with $25(\mathrm{OH}) \mathrm{D} 2$ was less than $10 \%$, and the analytical sensitivity was $10 \mathrm{nmol} / \mathrm{L}$. At present, the laboratory has no reference values for $25(\mathrm{OH}) \mathrm{D}$, but the manufacturer provides a population-based reference range of 27.7-107.0 nmol/L for adults as a guideline. This analysis was approved by the Norwegian Accreditation Authority. Because this method seems to overestimate serum $25(\mathrm{OH}) \mathrm{D}$ in smokers, we chose to exclude current smokers from the analysis [28].

In the interventional study, serum vitamin D was measured with in-house Liquid Chromatography-Tandem Mass Spectrometry (LC-MS/MS). The limit of detection was $<4 \mathrm{mmol} / \mathrm{L}$, and the between-day CV was $<9 \%$ [29]. Hs-CRP concentrations were measured using the turbid metric method. The reagents and the measuring device were provided by Roche Diagnostics. The total analytic CV was $4.26 \%$. HbA1c was measured with HighPerformance Liquid Chromatography (HPLC) using an automated analyzer (Variant II, Bio-Rad Laboratories Inc., Hercules, CA, USA). 


\section{Statistical analyses}

All statistical analyses were performed using IBM SPSS version 21 software. The distribution of continuous variables was evaluated by visual inspection of histograms and by kurtosis and skewness. Correlations were analysed using Pearson's correlation coefficient, and between-group comparisons were performed using ANOVA. The associations between serum 25(OH) D and hsCRP were analysed using the linear regression model, which was also used to test the interactions between variables.

In the interventional study, delta levels of hs-CRP were recorded for each year of intervention. The differences between delta values of hs-CRP in the vitamin D intervention group and the placebo group were evaluated with ANOVA. Furthermore, delta hs-CRP values for each year of the intervention were recorded in the dichotomous variables as follows: if the delta value was negative (indicating decreased hs-CRP), the dichotomous variable was coded as 1 . If the delta value of hs-CRP was zero or was positive (indicating no effect or increased hs-CRP), the dichotomous variable was coded as 2 . The logistic regression model was applied if intervention with vitamin D was a predictor of decreased hs-CRP during each year of the intervention after adjusting for age, sex, BMI, HbA1c and smoking status at baseline.

The data are presented as mean $\pm \mathrm{SD}$, unless otherwise specified. The significance level was set at $\mathrm{P}<0.05$ (two-tailed).

\section{Ethics}

The study was approved by the Norwegian Medicines Agency and by the Regional Committee for Medical Research Ethics. The trial is registered at ClinicalTrials.gov (NCT00685594).

\section{Results}

In the observational study, a total of 10,118 non-smoking subjects had available measurements of serum 25(OH) D and hsCRP. The demographics of the study population are provided in (Table 1). There were no significant differences in serum 25(OH) $\mathrm{D}$ and hs-CRP levels between the men and women. Men had significantly higher BMI, waist circumference and HbA1c.

Table 1: The demographic of the study population. The six Tromsø study, $n=10118$

\begin{tabular}{|c|c|c|c|}
\hline \multirow[b]{2}{*}{ Variables } & Men & Women & \multirow[b]{2}{*}{ P-value } \\
\hline & $n=4769$ & $n=5349$ & \\
\hline Age ( years) & $58 \pm 12$ & $58 \pm 13$ & 0.27 \\
\hline BMI $\left(\mathrm{kg} / \mathrm{m}^{2}\right)$ & $27.4 \pm 3.7$ & $26.3 \pm 4.7$ & $<0.001$ \\
\hline $\mathrm{HbA}_{1} \mathrm{c}(\%)$ & $5.7 \pm 0.7$ & $5.6 \pm 0.6$ & $<0.001$ \\
\hline Serum 25(OH)D (nmol /L) & $55.4 \pm 17.4$ & $54.7 \pm 18.1$ & 0.04 \\
\hline Serum hs-CRP ( $\mathrm{mg} / \mathrm{L})$ & $2.36 \pm 4.3$ & $2.41 \pm 4.65$ & 0.59 \\
\hline
\end{tabular}

In the total study population, there was a significant negative correlation between serum 25(OH) D and hs-CRP, resulting in a Pearson correlation coefficient $r$ of $-0.05(\mathrm{P}=0.001)$. In the linear regression model, after adjusting for age, sex, BMI, HbA1c and waist circumference, a $1 \mathrm{nmol} / \mathrm{L}$ increment in serum 25(OH)D resulted in a $0.02 \mathrm{mg} / \mathrm{L}$ decrease in hs-CRP $(\mathrm{P}=0.03)$. As there were significant interactions between BMI, serum 25(OH) D and sex, we performed a sex-stratified analysis. When analysing the genders separately, the negative association was statistically significant only in the women, resulting in a Pearson correlation coefficient $\mathrm{r}$ of $-0.06(\mathrm{P}=0.001)$ and a $\beta$ coefficient of -0.03 $(\mathrm{P}=0.03)$ (Table 2). With regard to the interventional study, the flowchart for this Randomized-Controlled Trial (RCT) is provided in (Figure 1). Five hundred fifty-six subjects were included, and 278 were randomly assigned to the placebo group. Twenty-two subjects who were allocated to the vitamin D intervention group and 23 who were allocated to the placebo group were excluded at the baseline visit (two did not meet the inclusion criteria, and 43 met one or more exclusion criteria). A total of 511 participants were finally included, 256 in the vitamin D group and 255 in the placebo group. At baseline, there were no significant correlations between hs-CRP and serum 25(OH) D levels (Pearson coefficient $\mathrm{r}$ of $-0.04 ; \mathrm{P}=0.35$ ). On the regression model, there was a negative but not statistically significant association between hs-CRP and serum $25(\mathrm{OH}) \mathrm{D}$ concentration after adjusting for age, sex, BMI, HbA1c and smoking ( $\beta$ coefficient of $-0.06 ; \mathrm{P}=0.22$ ).

\section{Effects of intervention}

At baseline, there were no differences between the vitamin D group and the placebo group with regard to age $(68 \pm 8$ years and $68 \pm 9$ years, respectively) and sex (63\% males and $60 \%$ females, respectively). There was also no difference in vitamin D supplement use $(\mathrm{n}=87$ [34.0\%] in the vitamin $\mathrm{D}$ group versus $\mathrm{n}=92[36.1 \%]$ in the placebo group). The baseline values and the values after each year of intervention are presented in (Table 3). There were no significant differences between the vitamin D and placebo groups in delta values of hs-CRP during any part of the 5-year intervention (Table 4).

In the logistic regression model, vitamin D intervention was associated with an increased odds ratio for delta hs-CRP of $>0$ for each year of intervention; however, the statistical significance of 
High-Sensitivity CRP is Associated with Serum 25-Hydroxyvitamin D Levels, but is not Affected by 5-Year Supplementation with Cholecalciferol

Table 2: Pearson's correlation coefficient $r$ and standardized coefficients $\beta$ from the linear regression model with hs-CRP (mg/L) as a depended variable. The sixth Tromsø study, $\mathrm{n}=10118$.

\begin{tabular}{|l|l|l|l|l}
\hline & $\boldsymbol{r}$ & P-value & $\beta^{*}$ \\
\hline
\end{tabular}

\begin{tabular}{|c|c|c|c|c|}
\hline \multicolumn{5}{|c|}{ Men, $n=4769$} \\
\hline Age & 0.1 & $<0.001$ & 0.07 & $<0.001$ \\
\hline BMI & 0.12 & $<0.001$ & 0.04 & 0.11 \\
\hline Waist circumference & 0.13 & $<0.001$ & 0.08 & 0.004 \\
\hline HbA1c & 0.09 & $<0.001$ & 0.04 & 0.008 \\
\hline $25(O H) D$ & -0.01 & 0.65 & -0.004 & 0.81 \\
\hline
\end{tabular}

\section{Women, $n=5349$}

\begin{tabular}{|c|c|c|c|c|}
\hline Age & 0.09 & $<0.001$ & 0.05 & 0.001 \\
\hline BMI & 0.22 & $<0.001$ & 0.15 & $<0.001$ \\
\hline Waist circumference & 0.2 & $<0.001$ & 0.05 & 0.04 \\
\hline $\mathrm{HbA}_{1} \mathrm{c}$ & 0.13 & $<0.001$ & 0.05 & 0.001 \\
\hline $25(O H) D$ & -0.06 & $<0.001$ & -0.03 & 0.03 \\
\hline
\end{tabular}

$* \beta$ adjusted for the other variables in the table

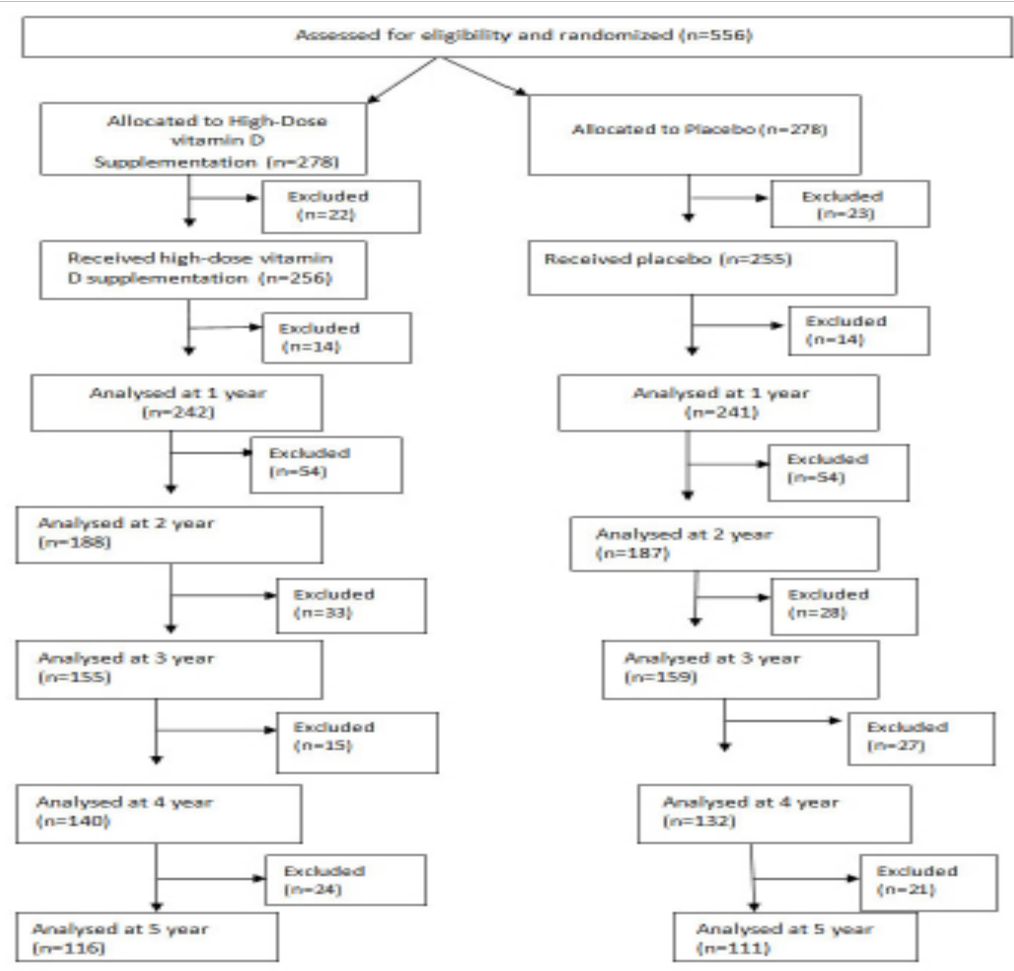

Figure 1: The flowchart of the study population. Interventional Study, $n=556$

Citation: Julia B, Rolf J, Kamycheva E (2017) High-Sensitivity CRP is Associated with Serum 25-Hydroxyvitamin D Levels, but is not Affected by 5-Year Supplementation with Cholecalciferol. J Nutrition Health Food Sci 5(5): 1-8. D0I: http://dx.doi. 
High-Sensitivity CRP is Associated with Serum 25-Hydroxyvitamin D Levels, but is not Affected by 5-Year Supplementation with Cholecalciferol

\begin{tabular}{|c|c|c|c|c|c|c|c|c|c|c|c|c|}
\hline \multirow[t]{2}{*}{ Variables } & & Baseline & & 1 year & & 2 year & & 3 year & & 4 year & & 5 year \\
\hline & $\begin{array}{c}\text { Vitamin } \\
\text { D } \\
(n=256)\end{array}$ & $\begin{array}{l}\text { Placebo } \\
(n=255)\end{array}$ & $\begin{array}{c}\text { Vitamin D } \\
(n=242)\end{array}$ & $\begin{array}{l}\text { Placebo } \\
(n=241)\end{array}$ & $\begin{array}{c}\text { Vitamin D } \\
(n=188)\end{array}$ & $\begin{array}{l}\text { Placebo } \\
(n=187)\end{array}$ & $\begin{array}{c}\text { Vitamin } D \\
(n=155)\end{array}$ & $\begin{array}{l}\text { Placebo } \\
(n=159)\end{array}$ & $\begin{array}{c}\text { Vitamin D } \\
(n=140)\end{array}$ & $\begin{array}{l}\text { Placebo } \\
(n=132)\end{array}$ & $\begin{array}{c}\text { Vitamin D } \\
(n=116)\end{array}$ & $\begin{array}{l}\text { Placebo } \\
(n=111)\end{array}$ \\
\hline BMI $\left(\mathrm{kg} / \mathrm{m}^{2}\right)$ & $30.1 \pm 4.1$ & $29.8 \pm 4.4$ & $30.0 \pm 4.2$ & $29.8 \pm 4.5$ & $29.9 \pm 4.3$ & $\begin{array}{c}29.7 \pm \\
4.6\end{array}$ & $29.8 \pm 4.2$ & $29.7 \pm 4.8$ & $29.5 \pm 4.3$ & $29.4 \pm 4.5$ & $29.2 \pm 4.2$ & $29.5 \pm 4.0$ \\
\hline $\begin{array}{c}\text { Current } \\
\text { smokers (n } \\
(\%))\end{array}$ & $59(23.0)$ & $47(18.3)$ & $51(21.1)$ & 45 (18.7) & $34(18.3)$ & $32(17.5)$ & $30(19.6)$ & 30 (18.9) & $21(15.6)$ & 17 (12.7) & $19(16.7)$ & $11(10.3)$ \\
\hline $\begin{array}{c}\text { Serum } \\
25(0 \mathrm{H}) \mathrm{D} \\
(\mathrm{nmol} / \mathrm{L})\end{array}$ & $59.9 \pm 21.9$ & $61.1 \pm 21.2$ & $105.6 \pm 27.7$ & $65.0 \pm 22.3$ & $110.4 \pm 24.0$ & $63.0 \pm 19.4$ & $115.4 \pm 26.5$ & $66.6 \pm 20.7$ & $117.7 \pm 26.7$ & $64.7 \pm 19.1$ & $122.3 \pm 25.3$ & $66.7 \pm 18.6$ \\
\hline $\mathrm{HbA}_{1} \mathrm{c}(\%)$ & $5.98 \pm 0.28$ & $5.97 \pm 0.34$ & $6.10 \pm 0.33$ & $6.09 \pm 0.43$ & $6.00 \pm 0.30$ & $5.96 \pm 0.32$ & $6.00 \pm 0.30$ & $5.98 \pm 0.55$ & $6.01 \pm 0.31$ & $5.96 \pm 0.34$ & $5.94 \pm 0.30$ & $5.91 \pm 0.29$ \\
\hline
\end{tabular}

Table 4: The delta values for hs-CRP for each year during the 5-year intervention in the vitamin D and placebo groups. The Tromsø vitamin D and T2DM trial.

\begin{tabular}{|l|c|c|c|}
\hline & \multicolumn{2}{|c|}{ Delta hs-CRP } & \multirow{2}{*}{ P-value } \\
\hline 1 year & Vitamin D group & Placebo group & 0.51 \\
\hline 2 year & $-0.52 \pm 5.36$ & $-1.08 \pm 12.02$ & 0.59 \\
\hline 3 year & $-0.40 \pm 5.15$ & $-0.98 \pm 13.62$ & 0.23 \\
\hline 4 year & $-0.20 \pm 6.33$ & $-1.58 \pm 12.85$ & 0.24 \\
\hline 5 year & $-0.42 \pm 5.23$ & $-1.90 \pm 13.83$ & 0.50 \\
\hline
\end{tabular}

Table 5: The odds ratios and their 95\% confidential interval from the logistic regression model with the dichotomous delta hs-CRP as a dependent variable and intervention group as a predictor with placebo group as a reference. The Tromsø vitamin D and T2DM trial.

\begin{tabular}{|l|c|c|}
\hline & OR (95\% CI)* P-value & 0.34 \\
\hline $\mathbf{1}$ year & $1.19(0.84 ; 1.70)$ & 0.04 \\
\hline $\mathbf{2}$ year & $1.49(1.02 ; 2.19)$ & 0.82 \\
\hline $\mathbf{3}$ year & $1.05(0.69 ; 1.60)$ & 0.3 \\
\hline $\mathbf{4}$ year & $1.27(0 . .81 ; 1.98)$ & 0.39 \\
\hline 5 year & $1.24(0.75 ; 2.00)$ & \\
\hline *adjusted for age, sex, BMI, smoking status, HbA1c at baseline & & \\
\hline
\end{tabular}

this observation was only seen for delta values at the second year (Table 5). The association was adjusted for age, sex, BMI, HbA1c and smoking status at baseline.

\section{Discussion}

In our observational study, we demonstrated that in the nonsmoking population, a $1 \mathrm{nmol} / \mathrm{L}$ increment of serum $25(\mathrm{OH})$ $\mathrm{D}$ led to a $0.02 \mathrm{mg} / \mathrm{L}$ decrease in hs-CRP. This association remained statistically significant only in women after the sexstratified analysis. To investigate the causality of this association, we determined whether supplementation with 20,000 IU of cholecalciferol each week decreased hs-CRP levels during a 5-year intervention. At baseline, there was a negative but not significant association between serum $25(\mathrm{OH})$ D concentrations and hs-CRP in 556 subjects who were prediabetic but otherwise healthy. We found no hs-CRP-lowering effect from cholecalciferol 
supplementation; these findings were consistent for each year of the intervention and were independent of age, sex, BMI, HbA1c and smoking status. Thus, to our knowledge, our study is the first to investigate the exposure-outcome relationship between serum $25(\mathrm{OH}) \mathrm{D}$ and the inflammatory biomarker hs-CRP from both observational and causal perspectives.

Recent studies have suggested the role of $25(\mathrm{OH}) \mathrm{D}$ in lowintensity chronic inflammation in healthy and T2DM subjects $[30,31]$. To our knowledge, there have been few RCTs in which inflammatory biomarkers, including hs-CRP, were secondary outcomes [30]. Our interventional study (the Tromsø vitamin D and T2DM trial) is the only RCT to date with a follow-up period as long as 5 years. Our finding of a negative association between serum $25(\mathrm{OH}) \mathrm{D}$ and hs-CRP in the observational study is consistent with previous reports. An inverse association between serum $25(\mathrm{OH})$ D concentrations and hs-CRP was found in subjects with cardiovascular disease, middle-aged and older adults and subjects with overweight and obesity [32-34]. On the other hand, observational studies have demonstrated that the inverse correlation between serum $25(\mathrm{OH}) \mathrm{D}$ concentrations and hs-CRP is only significant in subjects with low CRP levels or those with insufficient serum $25(\mathrm{OH})$ D levels. Thus, in the U.S. National Health And Nutrition Examination Survey (NHANES) of 20012006 , there was a negative association between serum $25(\mathrm{OH})$ D concentration and CRP, showing a CRP decrease of $0.285 \mathrm{mg} / \mathrm{l}$ for each $10 \mathrm{ng} / \mathrm{ml}$ increase in serum 25(OH) D concentration, but only in subjects with serum 25(OH) D concentrations of $\leq 21 \mathrm{ng} / \mathrm{ml}$ [35]. Furthermore, Tepper et al. studied 358 healthy males and found that serum 25(OH)D levels were negatively associated with hs-CRP at a threshold of $14 \mathrm{ng} / \mathrm{ml}$. Mellenthin et al. in a large observational study based on 2,723 subjects, reported that the inverse correlation between serum 25(OH) D and hs-CRP was only present in subjects with serum $25(\mathrm{OH})$ D levels of $<21 \mathrm{ng} / \mathrm{ml}$. Interestingly, when they further stratified the population according to smoking status, the association was no longer significant in non-smokers $(n=2,005)$ [36,37]. This particular observation is contrary to our study. However, we included a subgroup of non-smokers that was more than 5 -fold larger $(n=10,118)$; the lack of this association in non-smokers in Melenthin et al. Study can be explained by an insufficient number of subjects [37]. This association has a biologically plausible explanation: vitamin D binds to high-affinity Vitamin D Receptor (VDR) in mast cells, CD4 and CD8 lymphocytes, and macrophages, which may interfere with systemic inflammation and inhibit the production of several proinflammatory cytokines that modulate the tissue immune response and restrict inflammation $[38,39]$. Nuclear Factor Kappa B (NFkB) pathway-dependent transcriptional activation is a well-known signaling pathway in inflammation and a major regulator of the immune response. $\mathrm{NF} \kappa \mathrm{B}$ activation is also involved in endogenous CRP induction. The biologically active form of vitamin D, 1, 25-dihydroxyvitamin D3 $(1,25(\mathrm{OH}) 2 \mathrm{D} 3)$, can inhibit NF-kB activation in macrophages by up regulating the $\mathrm{NFKB}$ inhibitor [40]. This suggests that promoting higher concentrations of serum 1, 25(OH) 2D may suppress CRP by interfering with the NFKB pathway. A similar action with cholecalciferol supplementation was expected, but we were unable to confirm these effects in our 5-year intervention.
Prior RCTs assessing whether vitamin D supplementation lowered hs-CRP levels reported inconsistent results [27, 4143]. A noteworthy meta-analysis of 10 RCTs involving a total of 924 participants demonstrated that vitamin D supplementation significantly reduced hs-CRP levels, by $1.08 \mathrm{mg} / \mathrm{L} \mathrm{(95 \%} \mathrm{CI}$ $-2.13,-0.03$ ), with evidence of heterogeneity. Interestingly, the largest reduction $(2.21 \mathrm{mg} / \mathrm{L}[95 \% \mathrm{CI},-3.50,-0.92])$ occurred in individuals with baseline hs-CRP levels of $>5 \mathrm{mg} / \mathrm{L}$ [30]. Moreover, Tarcin et al. found that 3-month supplementation with vitamin D in subjects with very low serum 25(OH)D (mean $=10$ $\mathrm{ng} / \mathrm{ml}$ ) led to improved endothelial function and a decrease in markers of oxidative stress and insulin sensitivity[44].

Jablonski et al. studied vascular endothelial function in subjects aged 50-79 years both with and without vitamin D insufficiency (cut-off serum 25(OH)D level of $29 \mathrm{ng} / \mathrm{ml}$ ) [33]. Those with insufficient serum $25(\mathrm{OH})$ D levels demonstrated $29 \%$ lower $(\mathrm{P}<0.05)$ brachial artery flow-mediated dilatation (a measure of endothelial dysfunction) compared to their vitamin D-sufficient counterparts. Moreover, the vitamin D-deficient subjects (serum $25(\mathrm{OH}) \mathrm{D}<20 \mathrm{ng} / \mathrm{ml}$ ) had significantly higher expression of the proinflammatory cytokines NFKB and IL-6; however, no effect on TNF- $\alpha$ was seen.

In our prior RCT, overweight and obese subjects were randomised into three groups: the DD group (40,000 IU cholecalciferol per week), the DP group $(20,000$ IU cholecalciferol per week) and the PP group (placebo) [41]. The intervention period was one year, and the proinflammatory cytokines IL-6, TNF- $\alpha$ and hs-CRP were secondary outcomes. Consistent with the study by Jablonski et al. we found an effect of vitamin D supplementation on IL-6 lowering when the DD and DP groups were analysed together, but there were no significant changes in TNF- $\alpha$ [33]. Interestingly, we found an increment in hs-CRP after one year of cholecalciferol supplementation in overweight/ obese subjects. In the present study, we observed that after the second year of intervention, supplementation with 20,000 IU of cholecalciferol was associated with an almost $50 \%$ increase in the odds ratio of zero/positive delta hs-CRP values, and the participants had prediabetes. Since the same observation was not made after other intervention years, this finding was most likely due to chance or other factors (including ongoing proinflammatory conditions such as obesity or prediabetes) and should be treated with caution, at least in subjects with conditions such as prediabetes, overweight and obesity.

Our study has some potential limitations. The first and major limitation regards the interventional part of our study. The statistical power calculation was based on the hypothesis that T2DM would be prevented by cholecalciferol supplementation, and the primary outcome was the occurrence of T2DM. Second, when using inflammatory biomarkers as an outcome in both the observational and the interventional studies, it would be helpful to have data on whether the subjects were using Non Steroidal Anti-Inflammatory Drugs (e.g. NSAIDS) or had any inflammatory conditions (e.g. infection, latent autoimmune disease). This information was absent in our study. Finally, our intervention was performed on subjects with prediabetes, which is per se a 
proinflammatory condition and might interfere with any potential action of cholecalciferol in reducing levels of proinflammatory cytokines and biomarkers.

In conclusion, our observational study supported the current knowledge on the association between serum $25(\mathrm{OH}) \mathrm{D}$ and hs-CRP; however, the interventional study did not confirm the causality of the association and mitigates its clinical importance. Future RCTs are necessary, especially involving vitamin D-deficient subjects.

\section{Declarations}

\section{Competing interests}

The authors declare that they have no competing interests.

\section{Funding}

Julia Beilfuss has received grant from the Norwegian Health Authority.

\section{Author's contributions and consent to publish}

Conception and study design: JB, EK

Data collection: JB, RJ

Data analyses: JB

JB and EK drafted the manuscript.

Data interpretation, discussion and preparation of the final manuscript: JK, RJ, EK.

All authors read and approved the final manuscript. All authors have consented to publish.

\section{Ethics, consent and permissions}

The Regional Committee for Medical and Health Research Ethics approved the sixth Tromsø Study (ref: REK 2010/876), and the Tromsø vitamin D and type 2 Diabetes trial (ref: REK 2010/2182). All participants gave their written consent to participate. Trial registration at Clinical Trials.gov (NCT00685594).

\section{Availability of data and materials}

Data for the observational study (the sixth Troms $\emptyset$ study) is the property of UiT/Arctic University of Troms $\emptyset$ and is available upon request at: https://uit.no/forskning/forskningsgrupper/ gruppe?p_document_id=367276. The data file for the interventional study is the property of Professor Rolf Jorde, and is available upon the request to rolf.jorde@unn.no

\section{References}

1. Holick MF, Chen TC, Lu Z, Sauter E. Vitamin D and Skin Physiology: A D-Lightful Story. J Bone Miner Res. 2007;22(2):V28-33. doi: 10.1359/ jbmr.07s211

2. Adams JS, Hewison M. Unexpected actions of vitamin D: new perspectives on the regulation of innate and adaptive immunity. Nat Clin Pract Endocrinol Metab. 2008;4(2):80-90. doi: 10.1038/ ncpendmet0716

3. Holick MF. The Vitamin D Epidemic and its Health Consequences. J Nutr. 2005;135(11):2739S-2748S.
4. Lagunova Z, Porojnicu AC, Grant WB, Bruland Ø, Moan JE. Obesity and increased risk of cancer: Does decrease of serum 25-hydroxyvitamin D level with increasing body mass index explain some of the association? Mol Nutr Food Res. 2010;54(8):1127-1133. doi: 10.1002/ mnfr.200900512

5. White JH. Vitamin D Signaling, Infectious Diseases, and Regulation of Innate Immunity. Infect Immun. 2008;76(9):3837-3843. doi: 10.1128/ IAI.00353-08

6. Zittermann A. Vitamin $D$ in preventive medicine: are we ignoring the evidence? Br J Nutr. 2003;89(5):552-572. doi: 10.1079/BJN2003837

7. Hyppönen E, Läärä E, Reunanen A, Järvelin M-R, Virtanen SM. Intake of vitamin $\mathrm{D}$ and risk of type 1 diabetes: a birth-cohort study. Lancet. 2001;358(9292):1500-1503.

8. Kabadi SM, Lee BK, Liu L. Joint Effects of Obesity and Vitamin D Insufficiency on Insulin Resistance and Type 2 Diabetes: Results from the NHANES 2001-2006. Diabetes Care. 2012;35(10):2048-2054. doi: $10.2337 / \mathrm{dc} 12-0235$

9. Parker J, Hashmi O, Dutton D, Mavrodaris A, Stranges S, Kandala NB, et al. Levels of vitamin $\mathrm{D}$ and cardiometabolic disorders: systematic review and meta-analysis. Maturitas. 2010, 65(3):225-236. doi: 10.1016/j.maturitas.2009.12.013

10. Reis JP, von Mühlen D, Miller ER, Michos ED, Appel LJ. Vitamin D Status and Cardio metabolic Risk Factors in the United States Adolescent Population. Pediatrics. 2009;124(3):e371-e379. doi: 10.1542/ peds.2009-0213

11. Libby P. Inflammation in atherosclerosis. Nature. 2002;420(6917):86874. doi: $10.1038 /$ nature 01323

12. Lowe GDO. The Relationship Between Infection, Inflammation, and Cardiovascular Disease: An Overview. Ann Periodontol. 2001;6(1):18. doi: 10.1902/annals.2001.6.1.1

13. Kushner I. The phenomenon of the acute phase response. Ann N Y Acad Sci. 1982;389(1):39-48.

14. Mackiewicz A, Schooltink H, Heinrich PC, Rose-John S. Complex of soluble human IL-6-receptor/IL-6 up-regulates expression of acutephase proteins. J Immunol. 1992, 149(6):2021-2027.

15. Den Engelsen C, Koekkoek PS, Gorter KJ, van den Donk M, Salomé PL, Rutten GE. High-sensitivity C-reactive protein to detect metabolic syndrome in a centrally obese population: a cross-sectional analysis. Cardiovascular Diabetology. 2012;11:25

16. Ridker PM, Hennekens CH, Buring JE, Rifai N. C-reactive protein and other markers of inflammation in the prediction of cardiovascular disease in women. N Engl J Med. 2000;342(12):836-843. doi: 10.1056/ NEJM200003233421202

17. Yudkin JS, Stehouwer CD, Emeis JJ, Coppack SW. C-reactive protein in healthy subjects: associations with obesity, insulin resistance, and endothelial dysfunction: a potential role fo cytokines originating from adipose tissue? Arterioscler Thromb Vasc Biol. 1999;19(4):972-978.

18. Brahimaj A, Ligthart S, Ghanbari M, Ikram MA, Hofman A, Franco OH, et al. Novel inflammatory markers for incident pre-diabetes and type 2 diabetes: the Rotterdam Study. Eur J Epidemiol. 2017;32(3):217-226. doi: 10.1007/s10654-017-0236-0

19. Dehghan A, Kardys I, de Maat MP, Uitterlinden AG, Sijbrands EJ, Bootsma $\mathrm{AH}$, et al. Genetic variation, C-reactive protein levels, and incidence of diabetes. Diabetes. 2007;56(3):872-878. doi: 10.2337/ db06-0922 
20. Kushner I, Samols D, Magrey M. A unifying biologic explanation for "high-sensitivity" C-reactive protein and "low-grade" inflammation. Arthritis Care Res (Hoboken). 2010;62(4):442-446. doi: 10.1002/ acr.20052

21. Nanri A, Moore MA, Kono S. Impact of C-reactive protein on disease risk and its relation to dietary factors. Asian Pac J Cancer Prev. 2007;8(2):167-177.

22. Haque UJ, Bathon JM, Giles JT. Association of vitamin D with cardiometabolic risk factors in rheumatoid arthritis. Arthritis Care Res (Hoboken). 2012;64(10):1497-1504. doi: 10.1002/acr.21715

23. Jorgensen SP, Agnholt J, Glerup H, Lyhne S, Villadsen GE, Hvas CL, et al Clinical trial: vitamin D3 treatment in Crohn's disease - a randomized double-blind placebo-controlled study. Aliment Pharmacol Ther. 2010;32(3):377-383. doi: 10.1111/j.1365-2036.2010.04355.x

24. Patel S, Farragher T, Berry J, Bunn D, Silman A, Symmons D. Association between serum vitamin $D$ metabolite levels and disease activity in patients with early inflammatory polyarthritis. Arthritis Rheum. 2007;56(7):2143-2149. doi: 10.1002/art.22722

25. Forde OH, Thelle DS. The Tromso heart study: risk factors for coronary heart disease related to the occurrence of myocardial infarction in first degree relatives. American journal of epidemiology. 1977;105(3):192199. doi: 10.1093/oxfordjournals.aje.a112375

26. Jacobsen BK, Eggen AE, Mathiesen EB, Wilsgaard T, Njolstad I. Cohort profile: the Tromso Study. Int J Epidemiol. 2012;41(4):961-967. doi: 10.1093/ije/dyr049

27. Sollid ST, Hutchinson MY, Fuskevag OM, Figenschau Y, Joakimsen RM, Schirmer H, et al. No effect of high-dose vitamin D supplementation on glycemic status or cardiovascular risk factors in subjects with prediabetes. Diabetes care. 2014;37(8):2123-2131. doi: 10.2337/ dc14-0218

28. Grimnes G, Almaas B, Eggen AE, Emaus N, Figenschau Y, Hopstock LA et al. Effect of smoking on the serum levels of 25-hydroxyvitamin D depends on the assay employed. Eur J Endocrinol. 2010;163(2):339348. doi: 10.1530/EJE-10-0150

29. Maunsell Z, Wright DJ, Rainbow SJ. Routine isotope-dilution liquid chromatography-tandem mass spectrometry assay for simultaneous measurement of the 25-hydroxy metabolites of vitamins D2 and D3. Clin chem. 2005;51(9):1683-1690. doi: 10.1373/clinchem.2005.052936

30. Chen N, Wan Z, Han SF, Li BY, Zhang ZL, Qin LQ. Effect of vitamin D supplementation on the level of circulating high-sensitivity C-reactive protein: a meta-analysis of randomized controlled trials. Nutrients. 2014;6(6):2206-2216. doi: 10.3390/nu6062206

31. Zhang M, Gao Y, Tian L, Zheng L, Wang X, Liu W, et al. Association of serum 25-hydroxyvitamin D3 with adipokines and inflammatory marker in persons with prediabetes mellitus. Clin chim acta. 2017;468:152-158. doi: 10.1016/j.cca.2017.02.022

32. Dobnig H, Pilz S, Scharnagl H, Renner W, Seelhorst U, Wellnitz B, et al. Independent association of low serum 25-hydroxyvitamin $d$ and 1,25-dihydroxyvitamin d levels with all-cause and cardiovascular mortality. Arch Intern Med. 2008;168(12):1340-1349. doi: 10.1001/ archinte.168.12.1340
33.Jablonski KL, Chonchol M, Pierce GL, Walker AE, Seals DR. 25-Hydroxyvitamin D deficiency is associated with inflammationlinked vascular endothelial dysfunction in middle-aged and older adults. Hypertension. 2011;57(1):63-69. doi: 10.1161/ HYPERTENSIONAHA.110.160929

34. Bellia A, Garcovich C, D’Adamo M, Lombardo M, Tesauro M, Donadel G, et al. Serum 25-hydroxyvitamin D levels are inversely associated with systemic inflammation in severe obese subjects. Internal and emergency medicine. 2013;8(1):33-40.

35. Amer M, Qayyum R. Relation between serum 25-hydroxyvitamin D and C-reactive protein in asymptomatic adults (from the continuous National Health and Nutrition Examination Survey 2001 to 2006). Am J Cardiol. 2012;109(2):226-230. doi: 10.1016/j.amjcard.2011.08.032

36. Tepper S, Shahar DR, Geva D, Avizohar O, Nodelman M, Segal E, et al. Identifying the threshold for vitamin $\mathrm{D}$ insufficiency in relation to cardiometabolic markers. Nutrition, metabolism, and cardiovascular diseases. 2014;24(5):489-494. doi: http://dx.doi.org/10.1016/j. numecd.2013.10.025

37. Mellenthin L, Wallaschofski H, Grotevendt A, Volzke H, Nauck M, Hannemann A. Association between serum vitamin D concentrations and inflammatory markers in the general adult population. Metabolism. 2014;63(8):1056-1062. doi: 10.1016/j.metabol.2014.05.002

38. Provvedini DM, Tsoukas CD, Deftos LJ, Manolagas SC. 1,25-dihydroxyvitamin D3 receptors in human leukocytes. Science. 1983;221(4616):1181-1183.

39. Veldman CM, Cantorna MT, DeLuca HF. Expression of 1,25-dihydroxyvitamin $D(3)$ receptor in the immune system. Arch Biochem Biophys. 2000;374(2):334-338. doi: 10.1006/ abbi.1999.1605

40. Song Y, Hong J, Liu D, Lin Q Lai G. 1,25-dihydroxyvitamin D3 inhibits nuclear factor kappa B activation by stabilizing inhibitor IkappaBalpha via mRNA stability and reduced phosphorylation in passively sensitized human airway smooth muscle cells. Scandinavian journal of immunology. 2013;77(2):109-116.

41. Beilfuss J, Berg V, Sneve M, Jorde R, Kamycheva E. Effects of a 1-year supplementation with cholecalciferol on interleukin-6, tumor necrosis factor-alpha and insulin resistance in overweight and obese subjects. Cytokine. 2012;60(3):870-874. doi: 10.1016/j.cyto.2012.07.032

42. Jorde R, Sneve M, Torjesen P, Figenschau Y. No improvement in cardiovascular risk factors in overweight and obese subjects after supplementation with vitamin D3 for 1 year. J Intern Med. 2010;267(5):462-472. doi: 10.1111/j.1365-2796.2009.02181.x

43.Zittermann A, Frisch S, Berthold HK, Gotting C, Kuhn J, Kleesiek K, et al. Vitamin D supplementation enhances the beneficial effects of weight loss on cardiovascular disease risk markers. Am J Clin Nutr. 2009; 89(5):1321-1327. doi: 10.3945/ajcn.2008.27004

44. Tarcin O, Yavuz DG, Ozben B, Telli A, Ogunc AV, Yuksel M, et al. Effect of vitamin D deficiency and replacement on endothelial function in asymptomatic subjects. J Clin Endocrinol Metab. 2009;94(10):40234030. doi: $10.1210 /$ jc.2008-1212 